\title{
Quo vadis, European Space Weather community?
}

Jean Lilensten ${ }^{1, *}$, Mateja Dumbović ${ }^{2}$, Luca Spogli ${ }^{3}$, Anna Belehaki ${ }^{4}$, Ronald Van der Linden ${ }^{5}$, Stefaan Poedts ${ }^{6,7}$, Teresa Barata $^{8}$, Mario M. Bisi ${ }^{9}$, Gaël Cessateur ${ }^{10}$, Erwin De Donder ${ }^{10}$, Antonio Guerrero ${ }^{11}$, Emilia Kilpua ${ }^{12}$, Marianna B. Korsos ${ }^{13,14}$, Rui F. Pinto ${ }^{15,16}$, Manuela Temmer ${ }^{17}$, Ioanna Tsagouri ${ }^{4}$, Jaroslav Urbár ${ }^{18,3}$, and Francesca Zuccarello ${ }^{19}$

${ }^{1}$ Institut de Planétologie et d'Astrophysique de Grenoble, CNRS - UGA, BP 53, 38041 Grenoble cedex 9, France

${ }^{2}$ Hvar Observatory, Faculty of Geodesy, University of Zagreb, Kačićeva 26, HR-10000 Zagreb, Croatia

${ }^{3}$ Istituto Nazionale di Geofisica e Vulcanologia, Via di Vigna Murata 605, 00143, Italy

${ }^{4}$ National Observatory of Athens, Institute of Astronomy, Astrophysics, Space Applications and Remote Sensing (IAASARS), Ionospheric Group Metaxa and Vas. Pavlou, 15236 Palaia Penteli, Greece

5 STCE, Royal Observatory of Belgium, Ringlaan 3, B-1180 Brussels, Belgium

${ }^{6}$ Centre for mathematical Plasma Astrophysics/Department of Mathematics, KU Leuven, Celestijnenlaan 200 B, 3001 Leuven, Belgium

${ }^{7}$ Institute of Physics, University of M. Curie-Skłodowska, Pl. M. Curie-Skłodowskiej 1, 20-031 Lublin, Poland

${ }^{8}$ Univ Coimbra, CITEUC - Center for Earth and Space Research of the University of Coimbra, Geophysical and Astronomical Observatory, 3040-004 Coimbra, Portugal

9 RAL Space, United Kingdom Research and Innovation - Science \& Technology Facilities Council - Rutherford Appleton Laboratory, Harwell Campus, Oxfordshire OX11 0QX, UK

${ }^{10}$ Royal Belgian Institute for Space Aeronomy, Avenue Circulaire 3, B-1180 Brussels, Belgium

${ }^{11}$ University of Alcala, Plaza San Diego s/n 28801, Alcalà de Henares, Madrid, Spain

12 Department of Physics, University of Helsinki, P.O. Box 4, Yliopistonkatu 3, 00014, Finland

13 Department of Astronomy, Eötvös Loránd University, Pázmány P. sétány 1/A, Budapest H-1117, Hungary

${ }^{14}$ Department of Physics, Aberystwyth University, Ceredigion, Cymru SY23 3BZ, UK

${ }^{15}$ LDE3, DAp/AIM, CEA Saclay, 91191 Gif-sur-Yvette, France

${ }^{16}$ Institut de Recherche en Astrophysique et Planétologie, CNRS, UPS, CNES, 9 Ave. du Colonel Roche, 31028 Toulouse, France

${ }^{17}$ Insitute of Physics, University of Graz, Universitätsplatz 5, $8010 \mathrm{Graz}$, Austria

${ }_{18}^{18}$ Institute of Atmospheric Physics CAS, Bocni II 1401, Prague 141 31, Czech Republic

${ }^{19}$ Dipartimento di Fisica e Astronomia "Ettore Majorana", Sezione Astrofisica, Università di Catania, Piazza Università, 2, 95131 Catania, Italy

Received 30 November 2020 / Accepted 28 February 2021

\begin{abstract}
This paper was written by a group of European researchers believing that now is the right time to frame the Space Weather and Space Climate discipline in Europe for future years. It is devoted to openly discussing the organisation and sustainability of the European Space Weather community and its assets in the (near) future. More specifically, we suggest that the European Space Weather community lacks a uniting organisation to help the community to sustain and develop the successful efforts made thus far. Our aim is not to draw a complete and exhaustive panorama of Space Weather throughout the world, nor even throughout Europe. It is not a new white paper on the science and applications: there exist many (e.g. Tsurutani BT et al. 2020. Nonlinear Processes Geophys 27(1): 75-119); nor another roadmap: several important have been published recently (e.g. Schrijver CJ et al. 2015. Adv Space Res 55(12): 27452807; Opgenoorth HJ et al. 2019. J Space Weather Space Clim 9: A37). Our aim is to question our practices and organisation in front of several changes that have occurred in the recent years and to set the ground to provide coordinated answers to these questions being posed in Europe, and to make these answers discussed throughout the world.

This group was assembled first through a series of sessions devoted to the sustainability of Space Weather research during the European Space Weather Week (ESWW) series of meetings, specifically: ESWW 14 (2017), ESWW 15 (2018), and ESWW 16 (2019). It then grew from discussions and personal contacts.
\end{abstract}

*Corresponding author: jean.lilensten@univ-grenoble-alpes.fr 
The authors do not pretend to identify the full range of opinions in Europe, although they do come from 13 different European countries with a large span of ages (around half are below the age of 40 years old at the time of writing) with a good gender balance ending with a diverse mix of young and motivated scientists and senior people who have played a role in shaping the Space Weather community in Europe. The questions and the propositions to organise Space Weather in Europe in the future result from their discussions through these meetings and through remote meetings during the pandemic. We wish to share them with all those who consider themselves as members of the European Space Weather community and/or are interested in its future and to propose actions. We do this, bearing in mind that Europe plays a key international role in Space Weather which extends beyond the ESA and EU/EC geographic area.

Keywords: Space Weather / programmatics / Europe

\section{Introduction}

Following some earlier rudimentary initiatives from the middle of the 20th century onwards, Space Weather activities really started off in Europe in the 90s with an initiative of the European Space Agency (ESA). Since then, it has been structured through different initiatives. Within the International Space Environment Service (ISES), several new regional warning centres were set up, and existing centres began expanding rapidly, starting limited forecasting operations around the year 2000. In 2004, a meeting series was created - the European Space Weather Week - followed by the Journal of Space Weather and Space Climate. The funding came from different sources, including the European Commission, the European agencies (amongst which the ESA remains the major actor), the national governmental agencies, and ever more through private sources. Since then, changes have occurred which have caused us to further question our practices. Some of these changes affect all scientific disciplines (e.g. global warming/climate change, pandemic, etc.) while others are more specific to Space Weather (e.g. fragmentation, etc.).

In a world facing several scientific, political, and social challenges, several questions deserve to be addressed such as:

- How to organise the research discipline in the future? How and why to maintain the momentum that allowed us, in less than 20 years, to start many successful projects?

- How to increase awareness among the various user communities (including the general public) and train/educate them about the impacts of Space Weather on operational systems and society?

- How to help the wider public (including policy makers, stakeholders, and end users) to better understand our methods and their advantages/limits?

- How to better link the user communities and the science? How to develop best practices and capitalise on recent experiences such as the developments of Space Weather services for aviation (e.g. in the frame of the activities of the PECASUS consortium, see Appendix)?

- How to enhance integrity of European efforts on this topic? Diversity is an asset, but many different practices can make things fragmented.

- And, in the frame of our aim, how to ensure that what was built up (our heritage/legacy) is properly handed over to new generations? How do we make Space Weather awareness permanently common throughout our society?

We first review the organisation of the Space Weather initiatives at the European level (Sect. 2) to underline the background from which the community can leverage to face the challenges of the near future, critically discussed in Section 3. Some of the actions to be undertaken for the Space Weather sustainability in Europe are summarised in Section 4, together with some ideas and possible solutions to move European Space Weather activities under the umbrella of a legal entity. Finally, recommendations to raise the discussion in the European Space Weather community are given in Section 5 .

All throughout this paper, we focus on Europe at large (see Footnote 1) being aware that Space Weather is truly global (world-wide) but with varying regional impacts. Thus, we think that due to such regional peculiarities, some of the solutions need to be implemented regionally and at different levels.

\section{Past organisation of Space Weather initiatives in Europe}

Space Weather is a relatively young discipline. Its rise is a mid-term process that led our technological society to realise that it is sensitive to solar activity and related impacts. All the major industries are indeed influenced by solar events: space (rockets, satellites); communications (ground-air, space-space, ground-ground); energy (power plants, power grids, pipelines); tourism (polar lights/aurorae, modern transit); transportation (air, maritime, but surprisingly also trains) and the ever-increasing autonomous mobility (such as autonomous vehicles); positioning with, amongst many, an application in oil drilling, precision agriculture and fishery, timing services (such as in the finance and telecommunications sectors), and of course the military. It is important to note that although the interaction between military, academia, and industry might yield successful Space Weather initiatives, such interaction was mostly lacking in Europe in the past.

In the 1990s, ESA decided to assess how important it was to invest in Space Weather. This resulted in two major consortia involving two major European companies (Alcatel and RAL) and in several initiatives. After investing first in a batch of initial applications through the Space Weather Applications Pilot Project, ESA launched a new programme called the Space Situational Awareness $\left(\mathrm{SSA}^{1}\right)$ Preparatory Programme in 2009 , including a segment dedicated to Space Weather, as a first step in the development of a European operational network of Space Weather Services. The strategy was to start from existing European capabilities and to work toward a federated Space Weather service-provision concept, whereby supporting the utilisation of and access to space research and services. The final

\footnotetext{
${ }^{1} \mathrm{https}$ ://swe.ssa.esa.int/
} 
goal was to provide, in a timely manner, the pertinent information in the correct format to the proper end users, in order to support them in mitigating the Space Weather effects on their operational systems, reducing costs and improving reliability. In the first three years (period 1) a Space Weather Coordination Centre was set up at the Space Pole in Brussels (Belgium) for monitoring the system and providing first line support to the users, together with the Space Weather Data Centre at Redu (Belgium) hosting data for analyses, model development, and scientific research, and a first set of precursor services. After this first period, the programme was extended by 3 years (period 2) to continue to build a prototype network and by the formation of five Expert Service Centres (ESCs) to concentrate on Solar Weather, Heliospheric Weather, Space Radiation, Ionospheric Weather, and Geomagnetic Conditions. Each ESC connects different expert groups, federates their Space Weather products, and ensures the quality and consistency of the information provided. New assets were federated as service building blocks based on network requirements formulated in terms of system, product, and some high-level customer requirements. From 2017 onward (period 3), the network further expanded with new products and capabilities, and enhancement of user interfaces and services. Today the network includes 29 preoperational services built on more than 200 products provided by more than 40 expert groups and counts more than 1000 registered users. Recently ESA started the Space Safety Programme (S2P) in which the Space Weather Service network will further grow and mature with the inclusion of new forecasting models (physics, empirical and machine learning based), an enhanced Space Weather data system and further tailoring to finally evolve into a fully operational network with a capability of providing customised services and on-call support outside normal working hours.

In parallel, in 2000 ESA created an ad hoc board, the "Space Weather Working Team" (SWWT ${ }^{2}$ ). The SWWT is a forum open to European experts in a variety of both scientific and applied fields related to Space Weather. It plays an important role in advising ESA in Space Weather strategy and acts as a forum for discussion amongst the European Space Weather community. The SWWT is responsible for promoting coordinated European Space Weather activities at both national and industry levels. The SWWT seeks to identify and discuss potential collaborations and/or synergies with other structures or organisations.

One recommendation that came out of the two consortia's studies (Alcatel and RAL) was to create a COST (COoperation in Science and Technology) action devoted to Space Weather. COST 724 was active from 2003 to 2007, and soon followed by COST ESO803 ${ }^{3}$ from 2008 to 2012. Apart from coordination and science, these two actions resulted in different achievements:

- A widely accepted definition of Space Weather: "Space Weather is the physical and phenomenological state of natural space environments. The associated discipline aims, through observation, monitoring, analysis and modelling, at understanding and predicting the state of the Sun, the interplanetary and planetary environments, and the solar and non-solar driven perturbations that affect them; and

\footnotetext{
2 https://swe.ssa.esa.int/web/guest/swwt

${ }^{3}$ https://www.cost.eu/actions/ES0803/
}

also at forecasting and nowcasting the possible impacts on biological and technological systems." This definition is now translated in more than 50 languages (Lilensten \& Belehaki, 2009).

- The development of the scientific background in order to create European operational Space Weather capacity, in the form of a joint forecasting centre serving pan-European needs, in full respect of the European spirit, which makes the mixture of different cultures its true strength. The coordinated strength of the European Space Weather scientist community helped to enhance the capacity of existing ISES regional warning centres (Brussels, Prague, Warsaw, Moscow, etc.) and supported the creation of new ones (Graz, Exeter, etc.) as well as the Collaborative Expert Centres (first ESA, and later UKRI STFC RAL Space). The momentum in these COST actions and naturally-following activities raised sufficient awareness to sustain the creation of strong research groups such as the Solar-Terrestrial Centre of Excellence $\left(\mathrm{STCE}^{4}\right)$ in Brussels. The STCE benefited initially from the will of Belgium to take the leadership in Space Weather research and monitoring. Nowadays, other countries follow, and Space Weather has become a discipline with general recognition throughout Europe.

- The annual meeting "European Space Weather Week" (ESWW). The first two meetings (2003 and 2004) took place at ESTEC in the Netherlands, then continued in Belgium until 2019 (ESWW 35-16 ${ }^{6}$ ). The planned 2020 meeting in Glasgow, Scotland (UK) ${ }^{7}$ was postponed to 25-29 October 2021 by the novel coronavirus (COVID-19) pandemic. Instead, an online meeting, the European Space Weather Symposium 2020 (ESWS2020) $^{8}$ was successfully held. In regular years, the ESWW meeting has increased its attendance and now welcomes more than 400 participants from the five inhabited continents. The online substitute did not fall short and achieved the same allowing participants to meet, present, and interact "virtually" .

- The Journal of Space Weather and Space Climate ${ }^{10}$ was established in 2010. With a two-year impact factor of 3.1 (in 2019), it is now amongst the internationally recognised journals in the discipline. It receives between 80 and 100 submissions per year, of which 50 to 60 are published. It is gold open access, including open data (if the authors allow) used in the papers. Each paper is reviewed by at least two reviewers. The editorial board includes 20 editors worldwide (and certainly not limited to Europe). The publisher is $\operatorname{EDPS}^{11}$.

Apart from the initiatives taken by the COST communities (24 countries), another step was undertaken to make Space Weather recognized as a major discipline. Through the ESWW, a set of three medals was created. ${ }^{12}$ Each of them are under the

\footnotetext{
${ }^{4}$ http://www.stce.be/

5 http://sidc.be/esww3/

${ }^{6} \mathrm{http}: / / w w w . s t c e . b e /$ esww16/

$7 \mathrm{http}: / /$ esww17.iopconfs.org/home

${ }^{8}$ http://esws2020.iopconfs.org/home

${ }^{9} \mathrm{http}: / /$ esws2020.iopconfs.org/recordings

${ }^{10} \mathrm{https}: / /$ www.swsc-journal.org/

${ }^{11} \mathrm{https}: / /$ www.edpsciences.org/en/

$12 \mathrm{http}: / /$ www.stce.be/esww2019/medals.php
} 
umbrella of an Academy of Sciences, namely Norway (Birkeland medal), Russia (Chizhevsky medal), and Belgium (Baron Marcel Nicolet medal). They are now recognised worldwide and receive nominations globally.

These ESA and EU-COST efforts have certainly played a major role in promoting Space Weather in Europe along with various other endeavours. The discipline plays an increasingly important role in the EU/EC Research programmes. The results of different research programs are available on Community Research and Development Information Service (CORDIS ${ }^{13}$ ). Searching "Space Weather" on CORDIS yields only 14 hits for Framework Program 6 (FP6), but already 214 hits for FP7, and even 311 in the Horizon 2020 (H2020) programme (values quoted are from December 2020). The same search for the term "solar physics" yields 10, 46, and 237 hits, for the FP6, FP7 and H2020 programmes, respectively. Limiting the search to "Projects" only, the term "Space Weather" yields 6 hits for FP6, 82 for FP7, and 45 for the almost-finished H2020 programme. Similarly, for "solar physics", one obtains 5, 10, and 18 hits for the programmes FP6, FP7, and H2020, respectively.

\section{What are the new challenges that Space Weather is facing?}

\subsection{Challenges specific to the discipline}

\subsubsection{What happens in the post-integration phase?}

The era extending from the first ESA initiatives in 1995 to the end of the COST ES803 action in 2012 can be qualified as a phase of construction and integration. Then, Space Weather in Europe evolved toward a multiplication of organisations resulting in a dispersion of forces. Apart from the SWWT, whose aim is mainly to advise ESA, there is no unifying platform in Europe where scientists, engineers, forecasters, and users can exchange their ideas and expertise. The other main groups are the JSWSC editorial board (about 20 persons from different continents) and the ESWW Program Committee (same number). These bodies do their best to represent the community. However, they are not coordinated in order to optimise this representation.

Another concern is about the possible loss of relevance that we may face. The public attention and funding is more eagerly invested in research related to imminent danger (recent example being Covid-19 related research, which, at this moment, is understandable). As in the Tartar Steppe (Buzzati, 1966), how to remain credible when the "big one" never shows up (i.e. Curto et al., 2016)? An extreme Space Weather event (e.g. of Carrington-size, Cliver \& Dietrich, 2013) is a persuasive motivator to fund research, but extremely rare. On the other hand, more nominal Space Weather from strong storms occurring a few times per solar cycle to moderate storms occurring on a monthly basis (Kilpua et al., 2017), while also highly important to understand, predict and mitigate, may seem less attractive as a research topic. In addition, some Space Weather service users have learned to cope with some threats coming from events of moderate intensity (e.g. hardening of spacecraft equipment,

\footnotetext{
$13 \mathrm{https} / / /$ cordis.europa.eu/
}

transformers of electric power network withstanding moderate GIC levels, etc.) (Hapgood et al., 2021).

\subsubsection{Space Weather, a multi-sector maturing discipline}

The European Space Weather community that is gathered around ESWW and JSWSC attracts people from academic, public, and industrial sectors, and is highly multidisciplinary as it involves not only solar-terrestrial research, but also technological, biological, medical and even economic and legal aspects (e.g. most forecast providers have disclaimers) and proprietary issues (e.g. patented methods and services).

The community is present within major scientific associations such as European Geosciences Union (EGU) and European Physical Society (EPS), as regular sessions on Space Weather are organised. However, the community is not organised as a separate division, unlike some other disciplines, and therefore can lack a clear coherence (Opgenoorth et al., 2019). For instance, in EPS, the European Solar Physics Division predominantly covers Space Weather and Space Climate topics, but related research might also be found in, e.g. the Environmental Physics Division or the High Energy \& Particle Physics Division. In EGU, things are somewhat better, as within the solar-terrestrial division Space Weather and Space Climate is recognised as one of the four main topics (which are: (i) Sun and Heliosphere, (ii) Magnetosphere, (iii) Ionosphere and Thermosphere, and (iv) Space Weather and Space Climate); however, it is also the only topic out of these four which does not have a science officer.

One identified reason for that situation is that Space Weather is difficult to place since it is such an overarching and interdisciplinary theme, which connects to topics in solar and heliospheric physics, solar-terrestrial physics, magnetospheric physics, etc. For example, most topics presented in Sun \& Heliosphere, Magnetosphere Ionosphere \& Thermosphere sessions can probably be considered part of Space Weather, in particular for understanding its physical foundations. However, many applications type studies within the other themes are often better suited in Space Weather.

Without a clear structure and coordination within the community, these various aspects are only loosely connected around the current common interest and have a high risk of falling apart.

\subsubsection{The Industry as a partner}

Industry is the main area affected by Space Weather hazards and at the same time it is therefore a major driver for the development of Space Weather products and services. Although there are industrial developments in Space Weather in Europe, the knowledge is mainly pushed forward by the scientific community and the industry sector still has to adapt it to its needs. Both communities have a common interest but different objectives and time-lines. In order to guarantee the proper scientific progress and to maximise the resulting exploitation, the value of the scientific knowledge has to be properly assessed with respect to the industry requirements.

The long European tradition of public service induces often the expectation from private players to get the solutions provided by researchers (i.e. the public sector) for free. 
The European community is ill-prepared to argue against that without collective leverage.

We believe that the scientific community should be involved in, e.g. public policy making. For instance, if in the near future a public investment would be foreseen to protect certain assets, the public would want an unbiased and independent opinion (from the expert scientists) on how to distribute it. ${ }^{14}$ Finally, the research community lacks a forum to exchange its best practices related to industrial needs. We give in the Appendix an example of a succesful product developed for the industry. It is clear to the co-authors of this article that a structure, where such experience could be debated and exchanged, would constitute true progress beneficial to all parties.

\subsubsection{The sustainable use of space}

Satellites in orbit are exposed to a harsh space environment, changing plasma conditions and drastically varying fluxes of energetic charged particles, both those originating from both solar eruptions and the Van Allen belts. The Space Weather conditions affect the lifetime of the satellites in their orbits through the changes in the atmospheric drag. By a better understanding and forecasting of Space Weather we can help in fighting against the increasing space debris and in guaranteeing the sustainable use of space. For example, Finland has a Centre of Excellence in Research of Sustainable Space funded by the Academy of Finland, directly targeting these issues.

\subsubsection{The machine learning changing our approach}

Machine Learning (ML) is deeply reshaping the way we do science. The geosciences and space science with wealth of open data are in particular suitable for ML approaches leading to new discoveries. As an example, ML is present in $10 \%$ of the papers published in the JSWSC (37 papers include ML over 371 published papers from its start to February 2021). This trend will certainly strengthen. A consequence is that colleagues outside of our community can now make significant contributions to the discipline. However, our community is still organised in a classical way. How will we adjust to that?

The Space Weather community will have to consider for example how to make the best use of our physical knowledge for selecting the suitable ML computational models, or for preventing partial knowledge of the data errors to induce significant systematic biases in the analysis.

\subsection{Challenges related to science in general}

\subsubsection{The challenges of climate change}

We cannot and must not ignore climate change. That must be amongst our permanent preoccupations. We also have a responsibility in front of humanity. In the near future, a citizen

\footnotetext{
${ }^{14}$ In the UK for example, with the ongoing developments of the UK Space Weather Strategy, scientists (as well as experts from other sectors) were consulted for inputs through a good interaction process and inputs from the independent expert group that advises the UK Government on all things Space Weather, namely the Space Environment Impacts Expert Group (SEIEG), thus ensuring those in the civil service responsible for delivering the final document have all the expert advice as required.
}

will ask us "what have you done to prevent the catastrophe?" We must be worthy of the confidence put in the researchers.

Other astrophysical communities have started to take action (e.g. Astronomers for Planet Earth ${ }^{15}$ ). Some recently evaluated the carbon footprints of our meetings (Burtscher et al., 2020), or laboratory practices (Jahnke et al., 2020) and even our large computer needs (Portegies Zwart, 2020). Our Space Weather community should not ignore these first questionings and should fast become organised to find the proper solutions adapted to its needs.

\subsubsection{The challenges of the pandemic}

COVID-19 forced new usages in our practices and will durably change our behaviours (such as the previous workingfrom-home comment). The pandemic and restrictions on travelling are likely to have a long-lasting impact, in particular on young researchers. Networking and collaborations are extremely hampered and there are delays in the work and studies. Remote meetings/conferences/workshops are less productive than being there in person for active debate. The pandemic likely also increases the burden of supervisors and has significantly decreased face-to-face interactions between students/postdocs and supervisors. Reduced research visits and attendance at conferences affect the possibilities that arise from presenting and viewing research results, such as obtaining postdoctoral positions and conducting experiments for special campaigns.

This pandemic is likely to be followed by other world hazards that will constitute brakes to the exchanges. However, it is of vital importance that activities such as summer/winter schools, seminars, and conferences continue despite the possible restrictions on travelling. The future activities could engage user-friendly and easily approachable online working tools and virtual meetings, such as for the aforementioned ESWS2020 online/virtual meeting (see Appendix).

\subsubsection{The challenges of the national politics}

Over the years since the 1990s, the approach has always been that of sharing and cooperation, which extended well beyond the European Union since Norway, Switzerland, Israel, Russia, Armenia, and Turkey (to name only some) participated in many of the projects cited here. We now face a situation that makes it difficult to maintain these principles. The British EU exit may be a threat to the future European Space Weather integration. The hardening of diplomatic relations between the EU and for example, Turkey, or even wars such as that of NagornoKarabash or Crimea also call into question the spirit of openness desired by the entire European scientific community and followed until then. In his book "The world of yesterday", Zweig (1952) insisted on the role that scientists have in sustaining peace. The new situation - politics, pandemics, global change - makes it more and more difficult to follow his recommendations.

\subsubsection{Education, training and outreach}

One of the priorities of the H2020 programme is education and training, which is fundamental for disseminating new

\footnotetext{
$\overline{15} \mathrm{https} / /$ astronomersforplanet.earth/
} 
science and knowledge. This idea is well reflected in the projects that have been funded within the scope of the H2020 program, in different calls and topics. All of them include several dissemination activities, for students and young researchers, and also for citizens and decision makers. ${ }^{16}$ We rely therefore on a long experience with education and outreach.

Space Weather has some peculiarities though. One of them is that it is a discipline at the interface between fundamental physics, applied science, and operational activities. In order to educate industrialists, a Space Weather school for engineers was created in 2013 . The IEEE $^{17}$ was contacted to support this initiative, but without success. This initiative therefore faced the difficulty to reach its student target and was stopped after three years. In the meantime, another similar initiative was started that grew bottom-up, with the same target audience. This is called the Space Weather Introductory Course (SWIC) ${ }^{18}$.

Another peculiarity of the Space Weather community is its worldwide character. No country is immune to its vagaries, including developing countries. To build partnership with developing countries is one of the main goals of the International Space Weather Initiative (ISWI). ${ }^{19}$ In Europe, one of the main bodies for such education exchanges is the Group for Education Europe - Africa $^{20}$ which aims to develop Space Physics and Space Weather related disciplines in developing countries as part of the United Nations for Basic Space Science Initiative. Through this initiative, eight schools were organised on Space Weather in Africa in the last ten years, and more than $20 \mathrm{PhD}$ theses were successfully defended by African students under a common African - European co-supervision. However, few European scientists are aware of such initiatives, while many would presumably engage in such efforts.

\footnotetext{
${ }^{16}$ Here are some examples of H2020 projects:

- Topic Space Weather: SWAMI (ongoing, 2 stakeholders and users meetings), ESC2RAD (ongoing), TechTIDE (finished; workshop and stakeholders meeting), EUHFORIA (ongoing), SafeSpace (ongoing, workshops with stakeholders) https://www.safespaceh2020.eu/).

- Domain Space: PAGER (ongoing, workshops with industry and government stakeholders), PROGRESS (2015-2018, summer school), HESPERIA (2015-2017, summer school, workshop and business meeting), MAtISSE (2016-2018), FLARECAST (20152017, workshops with stakeholders, science for citizen with 2 workshops for children) (https://cordis.europa.eu/project/id/ 707543/matisse.web.cern.ch/).

- Other topics: LOFAR (ongoing, online workshops), AIDA (ongoing, winter school, workshops) (https://cordis.europa.eu/ project/id/777442/lofar4sw.eu/wp/?page_id=203), AIDA (http:// www.aida-space.eu/).

- PITHIA-NRF (Network of Research Facilities for Plasmasphere, Themosphere and Ionosphere, joint research activities and access to the observing facilities for training and for conducting joint experiments).

- Projects with other outreach activities and dissemination actions: ForbMOD (https://swe.uni-graz.at/index.php/projects/forbmod-eumariecurie, 2017-2019, festival of science, newsletters), GREST (2015-2018, cartoon vídeo series, TV documentary and other promotional material (calendar, etc.) (ForMOD-//cordis.europa.eu/ project/id/745782, GREST (http://est-east.eu/grest/projects/grest).

17 https://www.ieee.org/

$18 \mathrm{http}: / /$ www.stce.be/nl/SWeC

19 http://iswi-secretariat.org/

$20 \mathrm{https}$ //www.girgea.org/en/
}

Recently, higher education in Europe has also been boosted through the excellence of the Marie Skłodowska-Curie Actions (MSCA), in particular through the Innovative Training Networks (ITNs), which "aim to train a new generation of creative, entrepreneurial and innovative early-stage researchers, able to face current and future challenges and to convert knowledge and ideas into products and services for economic and social benefit". ${ }^{21}$ In the Space Weather domain, two noticeable ITNs are represented by the Space Weather Awareness Training Network (SWATNET) ${ }^{22}$ and the Training REsearch and Applications Network to Support the Ultimate Real-Time High Accuracy EGNSS Solution (TREASURE) ${ }^{23}$ projects. The good practice of competing for MSCA-ITN, despite the high rate of failure to obtain funding, must be pursued also by leveraging and focusing on the multidisciplinary nature of Space Weather and on its closeness to society, markets, and industries.

In the education domain at the University level, the making of an International Masters degree on Space Weather shared by several universities can be a solution worth investigating. In this regard, lessons should be gained from the University of the Arctic (UArctic), ${ }^{24}$ a network of universities, colleges, research institutes, and other organisations concerned with education and research in and about the North. The North 2 North mobility program allows students to participate in classes in different universities around the Northern polar circle.

The Erasmus Mundus Joint Master Degree (EMJMD) ${ }^{25}$ programme can also be exploited in the near future. However, a consequence of the exit from EU is that the United Kingdom left the Erasmus program. Even upon promising the introduction of the so-called "Turing scheme" aimed at replacing it, such an event shows that creating this International Masters degree on Space Weather will need a strong will and a coordinated European effort beyond just the EU Member States. ${ }^{26}$ Here again, an overarching roof would help to expand and develop such activities and to foster efforts in dedicated actions and projects.

\subsubsection{Communication}

The communication of the scientific community is ever changing and evolving. For instance, various social-media avenues have become an important communication channel of the 21st century. Science and research are not exempt from it. Without the support and coordination of this type of communication within our community, it is left on a semi-personal basis.

Proper communication channels can be a relevant factor in obtaining a balance between data protection/licensing and free access to information and knowledge. Not all community members nominally have the same access to information, as it is often related to the national or institutional organisations. Thus, there should be a community effort to reduce such differences, e.g. via use of existing or newly-developed online repositories, social media, or other kinds of sharing platforms.

\footnotetext{
${ }^{21} \mathrm{https}: / /$ ec.europa.eu/research/participants/data/ref/h2020/wp/ 2018-2020/main/h2020-wp1820-msca_en.pdf

$22 \mathrm{https} / / /$ cordis.europa.eu/project/id/955620

${ }^{23} \mathrm{http}: / / w w w . t r e a s u r e-g n s s . e u /$

$24 \mathrm{https}$ ://www.uarctic.org/

25 https:/ec.europa.eu/programmes/erasmus-plus/opportunities/individuals/students/erasmus-mundus-joint-master-degrees_en

${ }^{26} \mathrm{https}$ //www.gov.uk/government/news/new-turing-scheme-to-support-thousands-of-students-to-study-and-work-abroad
} 
To build a European Space Weather Social Platform (ESWSP) could then be one of the most essential parts of our communication channels. The ESWSP could be a platform for social interaction for everyone; e.g. from young to senior researchers, users, industrial partners, etc. Such timely IT solutions could bring colleagues closer together as a community by increasing our collaboration networks with each other in a form of, e.g. blogs, chats, webinars, etc., organised around some predefined dedicated topics. The platform could also allow sharing of new ideas, help and guide each other in a number of aspects which further moves the European Space Weather community forward.

\section{Quo vadis European Space Weather community?}

After having reviewed the historical reasons that led to the current level of maturity of Space Weather science in Europe, and the challenges that the new era is posing, in this section we focus on the potential/possible solutions to organise and sustain the activities within the Space Weather community in the near future. We propose a federating structure as a possible solution to tackle the challenges described in the previous section. Such a structure would help the European Space Weather community to maintain its efforts, to sustain the discipline as a research one, but also to sustain and develop the successful efforts made so far. Such a structure would also be a forum to exchange our practices. It should allow the European Space Weather community as a whole to become stronger in international discussions and negotiations. Moreover, it should help in consolidating national Space Weather communities in European countries (and beyond) and help in their discussions and negotiations at a national level by disseminating best practices. Such a structure, independent from any funding agency and/or decision maker and/or individual country would have the authority to set its own internal rules and to make propositions to external parties. It would be able to protect and sustain the efforts made up to now and set new practices respecting the environment. It would request a clear set of rules, a board that represents the community at large, and a frequent renewal of this board, as well as of course, a budget to sustain its activities. This structure would be the natural ground pertaining to activities such as:

- Editorial activities: Recently, EDPS was taken over by the Chinese publisher "Science Press". The Science Press company ensures a full Independence to the EDPS publishing company. However, the JSWSC is a European Space Weather community initiative: the Publisher needs official representatives of this community to negotiate and discuss.

- As it stands now, the journal also depends on the few persons who created it who take the decisions. The legitimacy of these people (amongst which three are co-authors of this article) only depends on the confidence that the community has in them. This is not sustainable and must urgently be improved to a decision making structure which draws its legitimacy from the community and is more-frequently and transparently renewed.
- Organisation of the European Space Weather Week (ESWW): The ESWW Programme Committee (PC) is another independent permanent board in Europe. Although the PC members devoted efforts to open it, its organisation is not clear to most of the Space Weather actors. To sustain this meeting as a prominent worldwide rendez-vous in Space Weather research and beyond, its leadership in the community must be clarified so that the community can make the decisions and understand them.

- Awarding medals: The Space Weather and Space Climate medals are again an initiative of several individuals within the ESWW programme committee. They grew up rapidly thanks to the confidence of the community. Now, after almost a decade of their existence, it is a good time to take them to a next level, working to further increase their significance, value and prestige, to make them the equivalent of, e.g. the Fields medal and to potentially expand upon their scope and number.

- Education and outreach: There are many education and outreach initiatives involving the European Space Weather community, as described in detail in Section 3. In addition, there are many education and outreach initiatives limited by the size of the European countries, while they are sometimes of global importance. A specific European body would help them to develop and find funding. It would also help European Space Weather actors to better cooperate with Non-European specific international capabilities, e.g. COSPAR, UN COPUOS, URSI, SCOSTEP, etc. Finally, such a body could help students to visit the laboratories of other countries through an exchange program.

- Communication: The exchange of best practices for scientists, engineers, and particularly forecasters, remains very difficult. In Europe we lack a structure that allows direct and frequent sharing of experiences regardless of the country.

Along with the activities listed here, such a structure would finally - and maybe most importantly - be the right place to think of new practices more respectful of the Earth environment and sustainable in all aspects (these are discussed in more detail in Appendix). In what follows we examine different possibilities to establish such a structure (or a board of representatives), which should be reviewed and discussed by the community at large.

The new structure should not be restricted to scientists. It should include forecasters, end users, educators, and providers of Space Weather services. Scientists can take the initiative because of their strong experience in organising international boards, but they ought to devote efforts in involving other European Space Weather dedicated participants.

We are also fully aware that we maintain some ambiguity in using the word "Europe". The new board should not be restricted to the European Union, it should start with participants from European countries. Whether or not it should be open to countries outside Europe like a COST action, and what statuses should these countries have in this organisation must be the decision of the participants themselves.

\subsection{What are the options?}

A structure and a board of representatives (henceforth: a board) that fulfills criteria listed in the previous section must 
be established as some form of legal entity. Two options logically occur:

- The board can be established in the scope of an entirely new scientific association.

- The board can be established in the scope of some existing scientific association.

\subsubsection{An entirely new scientific association}

The most natural legal form for a new scientific association is the international not-for-profit association (INPA), similar to EGU or EPS. INPA is a not-for-profit association (NPA) with a substantial presence in multiple countries. Similarly as NPA, INPA can be registered in almost any country and the executive office can be in some other country (e.g. EGU is registered in France, has an office in Germany, and it predominantly organises meetings in Austria). However, it should be noted that INPA falls under the rules and regulations of the country where it is registered and different countries can have different regulations for NPA/INPA. Generally speaking, NPA/INPA has its own legal personality and, consequently, its own assets and liabilities. Moreover, it has a legal capacity to do things in its own name, for example employ staff, deliver services, enter into commercial contracts, and leases in its own name. The economic activities are permitted in NPA/INPA; however, any profits derived from economic activities must be attributed to the development of the non-commercial activities (thus they are "not-for-profit"). It should be noted though, that different countries might have slightly different regulations regarding the economic and other INPA activities and some might not even recognise INPA as a legal form ${ }^{27}$. Many INPA are registered in Brussels, because it is the seat of EU, much of EU's administration is located here, and in comparison with some other countries it is relatively simple and cheap to register an INPA in Belgium.

In Belgium the INPA is termed "association internationale sans but lucratif" (AISBL) and is defined as a group of natural or legal persons which pursues a selfless aim of international utility. The AISBL has its own legal personality, independent of that of its members, it has its own rights and obligations and its members have limited responsibility. Even without any capital investments or budget, the AISBL must comply with a certain number of accounting obligations. The registered office must be located in Belgium, whereas the executive office can be located elsewhere.

AISBL is made up of two bodies: the general assembly and the administrative body, where the statutes determine the form, composition and mode of operation of the administrative body. Naturally, the members of the Space Weather community would form a general assembly and thus control the statutes and by-laws of the AISBL, as well as the administrative body, which could manage the budget and perhaps other resources such as JSWSC, ESWW medals, and ESWW organisation.

\footnotetext{
27 A guide to establishing NPAs/NGOs in Europe may be downloaded at http://www.a4id.org/wp-content/uploads/2017/02/ EU-registration-options-for-UK-NGOs-post-Brexit-FINAL-PDF-1. pdf
}

\subsubsection{Joining an existing scientific association:}

We sent a letter of inquiry to the European Geosciences Union (EGU) and to the European Physical Society (EPS). The EGU answered that its statutes do not allow such a construct and membership of the Union is restricted to individuals. The response of the EPS is that such a board can be established in the scope of EPS, therefore, this option is elaborated further herein.

The possibility to join Institute of Electrical and Electronics Engineers (IEEE) was considered but not studied partly because IEEE is a worldwide association of which the Certificate of Incorporation was filed with the State of New York for the formation of IEEE as a corporation in the USA. Therefore, it cannot fulfill our aim to provide a platform to the European Space Weather community.

The EPS ${ }^{28}$ is a not-for-profit association which includes 42 National Physical Societies in Europe, individuals from all fields of physics and European research institutions. It is a federation of National Physical Societies. The main activities are to support meetings, to help in organising scientific journals, to award prizes and fellowships and to support diversity and inclusion in physics, especially the young scientists. EPS focuses strongly on supporting young scientists. A key action on this is the Young Mind project that covers young scientist from undergraduates to postdoctoral researchers with national sections.

As a legal entity, EPS is an INPA registered in France and has a statute, by-laws and a clear hierarchical structure consisting of an Executive Committee (elected by the Council), which establishes priorities, reviews and develops budgets, and pilots EPS activities. The Council reviews the activities of the Society, approves the annual accounts, and discusses priorities for the future. The scientific activities of EPS are organised through Divisions, Groups, and Sections. The Space Weather scientific community is already present under EPS, mainly in the scope of the European Solar Physics Division, which includes various Space Weather themes and promotes related research in its meetings and activities.

In their response to our letter of inquiry, EPS noted that the Space Weather community can organise itself as a stand alone Division (concerned with a specific field of physics e.g. High Energy Physics) or a stand alone Group (concerned with interdisciplinary aspects of physics, e.g. Computational Physics), or as a section of the EPS Solar Physics Division. Divisions, Groups, and Sections (D/G/S) are all autonomous, with statutes, by-laws and a clear hierarchical structure that act essentially under the loose rules of the EPS.

Within the EPS D/G/S, the Space Weather community would have a specific account in the EPS accounting system reserved to finance its activities, newsletters, student grants and prizes. Funds going in and out of the account would require the approval of the proposed Space Weather and Space Climate $\mathrm{D} / \mathrm{G} / \mathrm{S}$, and the funds could not be used by the EPS without this approval. However, if in the future the EPS would be wound up, the funds would be transferred to a new, or existing like-minded association. In addition, should the EPS encounter serious financial difficulties (unforeseen at present - early 2021 - as the EPS has reserves to cover two years of current operations without

\footnotetext{
${ }^{28}$ https://www.eps.org
} 
Table 1. Comparison of the control the Space Weather and Space Climate community might have over its resources in the scope of EPS and INPA $($ TBD $=$ to be decided $)$.

\begin{tabular}{lcccccccc}
\hline & Budget & ESWW & Medals & JSWSC & $\begin{array}{c}\text { Worldwide } \\
\text { visibility }\end{array}$ & $\begin{array}{c}\text { Negotiating } \\
\text { power }\end{array}$ & $\begin{array}{c}\text { Outreach } \\
\text { expansion }\end{array}$ \\
\hline EPS & Partial & Full & Partial & Partial & Immediate to build & High & Broad \\
INPA & Full & Full & Full & Full & & TBD & Into INPA \\
\hline
\end{tabular}

using funds reserved for $\mathrm{D} / \mathrm{G} / \mathrm{S})$, the funds may be used to pay the debts of the EPS.

One of the main tasks of EPS D/G/S is to organise annual (or regular) meetings and satellite events in the field and they can be organised in meetings of other EPS D/G/S. Therefore, a future Space Weather D/G/S would maintain full control of its meetings, i.e. ESWW. The role of EPS can be, upon the Space Weather D/G/S request, to help in the organisation by use of the EPS Conference Services Department.

EPS D/G/S also manage the award of their prizes (subject to endorsement by the EPS Executive Committee). The medalist selection would be autonomously organised by the Space Weather D/G/S. EPS could help with logistics of the organisation for the award of the prize, including drafting and distributing press releases, casting and engraving medals, and preparing diplomas. The prize name has to include "EPS" (e.g. EPSESWW award). If there are other co-sponsors, they can also be mentioned in the name of the prize.

One of the key functions of the EPS in the past year has been the publication of the report "The Importance of Physics to the Economies of Europe". This report covers a six-year period and it demonstrates that the importance of physics in our society is significant, and increasing. EPS also trains its member associations in speaking about physics to policymakers and to the general public. Divisions and Groups provide independent expertise and advice upon request, act as peer reviewers and referees, propose, organise and support conferences in physics, propose speakers for major EPS conferences, serve on editorial boards of publications, develop outreach activities for students and the general public, support measures to help physicists in less-favoured regions, and participate in, and profit from, EPS initiatives.

Finally, the EPS has a many years experience of excellent relations with EDPS. EDPS publishes EPS news magazine, "Europhysics News" (EPN), and are partners in the Europhysics letters (EPL), a physics letters journal published twice a month under the scientific responsibility of the EPS. Based on these long-term collaborations with EDPS, EPS would help the Space Weather community to sustain and organise the JSWSC. Within an agreement between the Space Weather D/G/S and EDPS, the Space Weather D/G/S may find in EPS a legal entity to own and/or handle the JSWSC.

\section{An attempt to benchmark}

In this section, we provide two possible ways to follow as concrete proposals of federating structure. We consider that the status quo and inaction is simply not an option and would likely doom the European Space Weather community to lose its independence and its ability to influence the future of the discipline in a suitable way. The two options are: to create our own INPA or to join EPS through a Division, a Group, or a Section. In what follows we briefly discuss the pros and cons of these two options.

They are summarised in Table 1. Possible weighting criteria, which supports a comparison between EPS and INPA options, are reported in Table 2.

\subsection{New association}

As a legal form for a new scientific association the best way is International not-for-profit association (similar to EGU or EPS), which can be registered in any country with the operating office in some other country. To our point of view, the Belgium AISBL is the best choice amongst the INPAs because Brussels is the seat of the EU, much of the EU's bureaucracy is situated there, many international not-for-profit organisations are registered here, and as a result it should be relatively simple to register compared to other countries.

PROs: The community keeps full control over the budget and its initiatives (the medals, ESWW, and JSWSC). The sustainability is then ensured and significance level (i.e. prestige) of the medals is kept (if not increased). This can lead to more incomes or benefit from the help of other institutions that will not see Space Weather and Space Climate as part of another society. Some fundings can go directly from Europe to the organisation. The uniqueness of ESWW and its completelyinclusive nature can also be maintained and sustained as required.

The STCE is willing to set up this IASBL if that would be the preferred choice, and other organisations/institutions are also undoubtedly willing to do so.

CONs: The complexity to establish it: a proper legal entity form needs to be found, where to register it, need of legal assistance, need of budget and coordination between legal aspects, and community needs/wishes. Since this would be a new organisation it would have to build its own worldwide visibility and outreach (educational as well as to the public) and thus may at the beginning have relatively low negotiating power.

\subsection{Part of EPS}

As a part of EPS, three options exist: a Division, a Group, or a Section. The difference between Groups and Division is their multidisciplinary approaches. A Group is focused on a specific topics (e.g. history of physics) while a Division is per se interdisciplinary. Joining an existing Division would again dilute Space Weather related activities and decrease its visibility. In this extent, should the Space Weather community create an action with EPS, it would be a specific Division in order to welcome all the scientists from the different Space Weather fields (solar, plasma, magnetosphere, ionosphere, thermosphere). 
Table 2. Weighting criteria to compare EPS and INPA (TBD = to be assesed in due course).

\begin{tabular}{|c|c|c|}
\hline Weighting criteria & EPS & INPA \\
\hline Capacity to increase visibility & $\begin{array}{l}\text { High. EPS is a well-established organisation } \\
\text { (since 1986). Through the EPS newsletter, we } \\
\text { have the capacity to reach a large community.* }\end{array}$ & $\begin{array}{l}\text { Low. This is at the beginning but it can increase } \\
\text { fast. }\end{array}$ \\
\hline Timing to set up & $\begin{array}{l}\text { Short. It should be relatively short, even if further } \\
\text { details from EPS are needed. }\end{array}$ & TBD. \\
\hline Representativeness & $\begin{array}{l}\text { Low. It may be low if people not coming from } \\
\text { physics (e.g. industry etc.) are unhappy with EPS. }\end{array}$ & High. High and customizable (industry in or not). \\
\hline Political weight & $\begin{array}{l}\text { High. EPS is a big and somewhat recognised non- } \\
\text { profit organisation. }\end{array}$ & $\begin{array}{l}\text { TBD. It must be built up, but will be high in the } \\
\text { future. }\end{array}$ \\
\hline Sustainability of the medals & $\begin{array}{l}\text { Medium to High. EPS has its prizes and SW } \\
\text { medals can be part of them. }\end{array}$ & $\begin{array}{l}\text { High. The medals are currently well recognised } \\
\text { and have impact/scholarship well beyond that of } \\
\text { Europe. }\end{array}$ \\
\hline Education sponsorship & $\begin{array}{l}\text { High. EPS-sponsored education activities include, } \\
\text { e.g. workshops for physics teachers. }\end{array}$ & $\begin{array}{l}\text { High. Our community already invests a lot in SW } \\
\text { education. }\end{array}$ \\
\hline Costs & Annual fee 25 EUR per person. & $\begin{array}{l}\text { Annual fee TBD (will depend on the business } \\
\text { model chosen) } \approx 150 \text { EUR of administrative costs } \\
\text { (one-time). }\end{array}$ \\
\hline
\end{tabular}

\footnotetext{
* It is important to note that by entering EPS we also help to increase the visibility of EPS.

Note that the weighting criteria listed here is likely biased by the fact that the authors are coming mainly from the academic sector and thus some criteria important to, e.g. end users, might be lacking. We hope to gain this feedback through public discussion (see Sect. 5.3).
}

Should the community choose to have a board under EPS as a roof organisation, expanding it later on into an independent INPA still remains a possibility.

PROs: to create an interdisciplinary Division within EPS is simple. Since EPS is old and well known, it would immediately give a worldwide platform to the European Space Weather community and be a strong kick to further develop our initiatives (medals, education, outreach, etc.) and be stronger in the future possible negotiations. The community would have full control over some of its initiatives (ESWW and the medals)

CONs: the limited control over decisions, and a risk of loss of significance of ESWW, JSWSC, and the medals constitute some points of vigilance. The community would have only partial control of the budget. EPS is not equally known nor equally respected by all European countries.

\subsection{Concluding remarks}

With this paper, we wish to start the initiative of further converging of the European Space Weather community and to raise awareness on its sustainability and possible future actions. In order to include the whole community into the discussion about its future, we invite those who consider themselves as members of the European Space Weather community and/or are interested in its future to participate in an online discussion which will be organised as a follow-up of the successful ESWS2020 online/virtual meeting/conference. In an online event for preregistered participants, we will provide a short overview of this paper followed by Q\&A type of discussion. In addition, the paper will be available as a Quick View at the meeting website and will remain open for online written comments/discussion after the online event, as an open forum. This event will take place long enough after this paper is published. Interested participants can send a mail to quovadis@SpaceWeather.eu to subscribe to a mailing list where further information will be distributed in due course.

Acknowledgements. Authors are grateful to the participants in the panel discussion held during the 1st Space Weather Workshop at the 8th Annual IEEE International Conference on Wireless for Space and Extreme Environments (WISEE 2020 - https://attend.ieee.org/wisee-2020/) for the useful discussion that inspired some parts of the paper. In particular, we thank Nicola Linty (Finnish Geospatial Research Institute), Wojciech Jacek Miloch (University of Oslo), Lucilla Alfonsi (Istituto Nazionale di Geofisica e Vulcanologia), Kirsti Kauristie (Finnish Metereological Institute), and Pierre Cilliers (South African National Space Agency) for their stimulating input. 


\section{References}

Burtscher L, Barret D, Borkar AP, Grinberg V, Jahnke K, Kendrew S, Maffey G, McCaughrean MJ. 2020. The carbon footprint of large astronomy meetings. Nat Astron 4: 823-825. https://doi.org/ 10.1038/s41550-020-1207-z.

Buzzati D. 1966. Il deserto dei Tartari, Arnoldo Mondatori Editore. ISBN 8804492953.

Cliver EW, Dietrich WF. 2013. The 1859 space weather event revisited: limits of extreme activity. J Space Weather Space Clim 3: A31. https://doi.org/10.1051/swsc/2013053.

Curto JJ, Castell J, Del Moral F. 2016. Sfe: waiting for the big one. J Space Weather Space Clim 6: A23. https://doi.org/10.1051/swsc/ 2016018.

Hapgood M, Angling MJ, Attrill G, Bisi M, Cannon PS, et al. 2021. Development of space weather reasonable worst case scenarios for the UK national risk assessment. Space Weather 2020SW002,593. https://doi.org/10.1029/2020SW002593.

Jahnke K, Fendt C, Fouesneau M, Georgiev I, Herbst T, et al. 2020. An astronomical institute's perspective on meeting the challenges of the climate crisis. Nat Astron 4: 812-815. https://doi.org/ 10.1038/s41550-020-1202-4.

Kilpua EKJ, Balogh A, von Steiger R, Liu YD. 2017. Geoeffective properties of solar transients and stream interaction regions. Space Sci Rev 212(3-4): 1271-1314. https://doi.org/10.1007/s11214017-0411-3.

Lilensten J, Belehaki A. 2009. Developing the scientific basis for monitoring, modelling and predicting space weather. Acta Geophys 57(1): 1-14. https://doi.org/10.2478/s11600-008-0081-3.

Opgenoorth HJ, Wimmer-Schweingruber RF, Belehaki A, Berghmans D, Hapgood M, et al. 2019. Assessment and recommendations for a consolidated European approach to space weather - as part of a global space weather effort. J Space Weather Space Clim 9: A37. https://doi. org/10.1051/swsc/2019033.

Portegies Zwart S. 2020. The ecological impact of high-performance computing in astrophysics. Nat Astron 4: 819-822. https://doi.org/ 10.1038/s41550-020-1208-y.

Schrijver CJ, Kauristie K, Aylward AD, Denardini CM, Gibson SE, et al. 2015. Understanding space weather to shield society: A global road map for 2015-2025 commissioned by COSPAR and ILWS. Adv Space Res 55(12): 2745-2807. https://doi.org/10.1016/ j.asr.2015.03.023.

Tsurutani BT, Lakhina GS, Hajra R. 2020. The physics of space weather/solar-terrestrial physics (STP): what we know now and what the current and future challenges are. Nonlinear Processes Geophys 27(1): 75-119. https://doi.org/10.5194/npg27-75-2020.

Zweig S. 1952. Die Welt von Gestern, Erinnerungen eines Europäers, S. Fischer, Frankfurt am Main. ISBN 978-3-10097047-3.

\section{Appendix}

In this section, we provide as appendices, insights about the use of virtual and face-to-face meetings and a proposal for a new kind of meeting that can be initiated following what we have all learned during the pandemic about the new way of conceiving meetings. In addition, we briefly describe a few notable European (or mainly European) actions addressing the link between Space Weather science and industry that are good examples for new initiatives in that sense.

\section{What new practices?}

During the pandemic, face-to-face meetings were gradually replaced by virtual meetings. The advantages of face-to-face over virtual meetings are that: (1) the participants have continuous and instant feedback; (2) colleagues come to know each other personally and understand each other better, which contributes to progress and information assimilation; (3) unexpected collaborations can be formed as a result of informal discussions. On the other hand, virtual meetings: (1) are more easily fitted in the work schedule, (2) provide meeting opportunity without depending on a specific venue, (3) reduce travel time and costs as well as the carbon footprint. Before deciding on the right way to promote face-to-face or virtual meetings, one should consult the targeted community, keeping in mind that by combining the two types of meetings, one can reach out most efficiently to more colleagues at a given time. To hold successful virtual meetings, suitable and reliable software is needed and preferably be supported by virtual poster sessions and parallel rooms.

In this regard, a new practice might be initiated. The week before the ESWW could become a Space Weather Working Week (SWWW). The local organiser would provide to the community at low cost meeting rooms, coffee breaks, reliable Internet connection, etc. The international community could gather at each participant's convenience to organise working meetings, to answer proposals, write papers, to make the regular progress reports requested in any international program, etc. Through such an organisation, the scientists would make one single travel and hold different working meetings with colleagues. The SWWW would then allow a strong momentum to be created within the community, through the construction of bridges between different projects. The weekend in between the SWWW and the ESWW could be used to visit the host city and surroundings, which we do less and less and could act to increase our knowledge of other cultures.

\section{Recent examples of Space Weather research - industry service: the IPS project, the PECASUS consortium and the ESA Space Safety Programme}

The link between Space Weather science and the industry is becoming tighter, as awareness grows of the impacts of Space Weather on technological systems in various operational domains. Translating scientific information into a language understandable for end users is quite a challenge, requiring Space Weather services/products that are highly tailored according to the needs of the specific user communities. As notable European examples, we briefly report on the features and the maturing experience in the frame of the Ionospheric Prediction Service (IPS) project and the global Space Weather service provided by the PECASUS Consortium and ESA Space Safety Programme (S2P). IPS is taken as an example of a service developed following the user-needs of specific communities, while PECASUS and S2P are likely to be the first Space Weather services provided from the research community to "big" customers such as ICAO and ESA.

The IPS project was an initiative of the European Commission in the framework of the Galileo Programme (ended in 2018). A prototype service has been designed and developed to translate ionospheric and solar nowcasting/forecasting in a way tailored for specific GNSS user communities: aviation, 
GNSS mass market, and high accuracy GNSS service providers. The system is currently running at the IPS web portal ${ }^{29}$.

The PECASUS consortium (Partnership for Excellence in Civil Aviation Space Weather User Services) ${ }^{30}$ is one of the three global centers providing Space Weather Advisories to the IN International Civil Aviation organisation (ICAO). The PECASUS consortium was born as a purely European consortium of nine institutions that was joined at a later stage by the South African National Space Agency. The consortium is currently operational whereby compiling and disseminating Space Weather information that is available within the consortium, into advisories - similarly to the traditional meteorological ones - in case of significant Space Weather events with impacts on aviation GNSS systems, HF communications and radiation levels at flight altitudes. This could pave the way to the provision of similarly-tailored services in which the European Space Weather Community must have a key role, especially regarding end user consultations in order to fully understand their needs. The new ESA Space Safety Programme (S2P) which is about to start its implementation, plans to test a variety of complementary Space Weather services for their 24/7 operational capacity in order to satisfy the requirements of ESA for comprehensive nowcasting and forecasting products that fully cover all aspects of Space Weather in the heliosphere, the magnetosphere, the ionosphere and the atmosphere, and be able therefore to support ESA's space operations and mission design.

Cite this article as: Lilensten J, Dumbović M, Spogli L, Belehaki A, Van der Linden R, et al. 2021. Quo vadis, European Space Weather community? J. Space Weather Space Clim. 11, 26. https://doi.org/10.1051/swsc/2021009.

\footnotetext{
${ }^{29} \mathrm{https}: / /$ ionospheric-prediction.jrc.ec.europa.eu/

${ }^{30} \mathrm{http}: / /$ pecasus.eu
} 